\title{
Short- and long-term outcomes after valve replacement surgery for rheumatic heart disease in the South Pacific, conducted by a fly-in/fly-out humanitarian surgical team: A 20-year retrospective study for the years 1991 to 2011
}

\author{
Linda Thomson Mangnall, MN (Hons), ${ }^{a}$ David Sibbritt, $\mathrm{PhD},{ }^{\mathrm{b}}$ Margaret Fry, $\mathrm{PhD},{ }^{\mathrm{b}}$ and \\ Robyn Gallagher, $\mathrm{PhD}^{\mathrm{b}}$
}

\begin{abstract}
Objectives: Fiji has one of the highest rates of rheumatic heart disease in the world. Humanitarian fly-in/fly-out surgical teams, including Open Heart International, have been conducting valve replacement surgery in Fiji since 1991. We sought to determine the short- and long-term outcomes of valve replacement for rheumatic heart disease.
\end{abstract}

\begin{abstract}
Methods: The Open Heart International team performed surgery on 167 patients from 1991 to 2011. Complete follow-up data to death or last evaluation on 149 patients $(89.2 \%)$ and morbidity data for 152 patients $(91 \%)$ were extracted from medical records.
\end{abstract}

\begin{abstract}
Results: Patients' average age at the time of surgery was 26.1 years, with the majority being female $(63.5 \%)$. Valves replaced were isolated mitral valves $(52 \%)$, isolated aortic valves $(19 \%)$, and multiple valves $(29 \%)$. The cumulative mortality rate at 30,60 , and 90 days and at 1,5 , and 10 years was $2.4 \%, 6.0 \%, 8.4 \%$, $12.0 \%, 19.8 \%$, and $23.9 \%$, respectively. Major adverse valve-related events-free survival was 10.1 years (95\% confidence interval [CI], 8.32-11.94). After adjusting for confounders, female patients were 3.03 times more likely to die postoperatively than male patients (odds ratio [OR], 3.03; 95\% CI, 1.23-7.69). Patients undergoing isolated valve replacement were less likely to have a morbidity event than those undergoing multiple valve replacement (isolated mitral $67 \%$ less likely [OR, 0.33; 95\% CI, 0.12-0.93] and isolated aortic 76\% less likely [OR, 0.34; 95\% CI, 0.06-0.96]).
\end{abstract}

Conclusions: The majority of people undergoing valve replacement for rheumatic heart disease have good outcomes. Mortality and morbidity rates at 1 and 5 years, particularly for female patients, are cause for concern and indicate a need for evaluation of resources toward systematic long-term postoperative surveillance and medical management. (J Thorac Cardiovasc Surg 2014;148:1996-2003)

Rheumatic heart disease (RHD) is a global health problem conservatively estimated as affecting 16 million people worldwide and continues to be a significant cause of mortality and morbidity in developing countries. ${ }^{1-3}$ Some $97 \%$ of all RHD occurs in developing countries and among indigenous populations of industrialized countries, primarily because pathogenesis is related to poverty, overcrowding, increased frequency of bacterial throat and skin infections, and decreased access to medical care. ${ }^{1,4}$

In contrast to global trends, data from South Pacific island countries indicate that the prevalence of RHD is increasing, ${ }^{2,5-9}$ and current prevalence ranges from

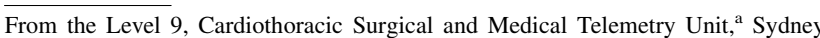
Adventist Hospital, Wahroonga, New South Wales, Australia; and Faculty of Health, ${ }^{\mathrm{b}}$ University of Technology, Sydney, New South Wales, Australia.

Disclosures: Authors have nothing to disclose with regard to commercial support.

Received for publication Feb 12, 2013; revisions received Aug 7, 2013; accepted for publication Feb 3, 2014; available ahead of print March 12, 2014.

Address for reprints: Linda Thomson Mangnall, MN (Hons), 185 Fox Valley Rd,

Wahroonga, NSW 2076, Australia (E-mail: linda.tm@sah.org.au).

$0022-5223 / \$ 36.00$

Copyright (c) 2014 by The American Association for Thoracic Surgery

http://dx.doi.org/10.1016/j.jtcvs.2014.02.006
33.2 per 1000 in the Kingdom of Tonga ${ }^{9}$ to 55.2 per 1000 in the Fiji Islands. ${ }^{7}$ Consequently, the Fiji Islands currently has the highest documented prevalence of RHD in the world, with children as young as 6 years old having RHD as the primary cause of death. ${ }^{5,10}$ Although there are a number of programs in place to manage and control RHD in Fiji, including prevention and screening campaigns, ${ }^{7,11,12}$ there remains an absence of in-country capability to provide valve replacement (VR) surgery for people who have severe RHD.

Strategies implemented in Fiji to provide VR surgery consist of transporting patients for surgery to other nearby countries and inviting fly-in/fly-out humanitarian teams in-country to perform the surgery. The latter is the most economic option for Fiji because these surgical teams are able to operate on approximately 8 patients for the same cost as sending 1 patient overseas for surgery.

VR surgery for RHD is major surgery; up to 3 valves may be replaced depending on the severity of the disease. ${ }^{13}$ Surgical risks include increased risk of morbidity or mortality from stroke, embolism, infection, and cardiac failure. ${ }^{13}$ Mechanical valves are primarily used on fly-in/fly-out 

Abbreviations and Acronyms
AVR = aortic valve replacement
$\mathrm{CI}=$ confidence interval
$\mathrm{CWMH}=$ Colonial War Memorial Hospital
INR = international normalized ratio
MAVE = major adverse valve-related event
MVR = mitral valve replacement
$\mathrm{OHI}=$ Open Heart International
$\mathrm{OR}=$ odds ratio
RHD = rheumatic heart disease
$\mathrm{VR}=$ valve replacement

missions because they are more durable, although there is an associated increase in risk of thromboembolic or hemorrhagic events due to the concomitant need for anticoagulation therapy. In addition, RHD and endocarditis prophylaxis, and cardiac rhythm and rate control are necessary. ${ }^{14,15}$ The risks of anticoagulation therapy are well recognized, with thromboembolic/hemorrhagic complications most likely to occur within the first 6 months after a mechanical VR. ${ }^{16}$ This means that although most patients are able to resume a fully active life after a 3-month recovery period, lifelong medical surveillance is required. ${ }^{14}$ Within this context, evaluation of longer-term postoperative outcomes after fly-in/ fly-out VR surgery is warranted.

There are little published data on short- and long-term follow-up of people who have undergone VR surgery for RHD disease in the South Pacific region or in other developing countries that use fly-in/fly-out humanitarian surgical teams as a key strategy. ${ }^{17,18}$ This retrospective study analyzed follow-up data collated from all patients who have undergone VR surgery for RHD performed by the Open Heart International (OHI) Team in Fiji (formerly known as Operation Open Heart) from 1991 to 2011. This evaluation will assist in identifying risk factors and facilitate tailoring of postoperative patient education to match identified needs. National and institutional Human Research Ethics Committee approval were obtained in Australia and Fiji before commencement of the study.

The study objectives were to identify the short- and longerterm outcomes after VR for RHD in Fiji for all-cause mortality, valve and RHD-related morbidity, and freedom from major adverse valve-related event (MAVE), ${ }^{19}$ and to determine the statistically significant factors associated with allcause mortality and valve and RHD-related morbidity for people after VR surgery for RHD.

\section{MATERIALS AND METHODS Setting and Participants}

The Fiji Islands are located in the South West Pacific and are composed of 332 islands, of which approximately one third are inhabited. The estimated population of 950,000 is mainly ethnic Fijian (57\%) and
Indo-Fijian (37\%), with the remaining 6\% including people of Caucasian, Chinese, and Rotuman ethnicities. ${ }^{20}$

The OHI humanitarian fly-in/fly-out surgical team is coordinated by the Sydney Adventist Hospital, located in Sydney, New South Wales, Australia. ${ }^{21}$ The team conducts VR surgery at the Colonial War Memorial Hospital (CWMH), the national referral hospital located in Suva, Fiji. Screening visits occur before the surgical team visit to evaluate prospective patients, referred by local physicians, for surgical selection. If screening indicates surgical need, the $\mathrm{OHI}$ cardiologists present the patient's history and echocardiograms at a video teleconference in Sydney to key OHI personnel, including surgeons, anesthetists, cardiac nurses, and the team leader. Prospective patients selected during the video teleconference are reevaluated on-site at CWMH before final selection. Dental review and extraction, if required, occur in-hospital as a component of the preoperative workup alongside antibiotic prophylaxis. Surgical exclusion criteria includes irreversible cardiac dysfunction, such as pulmonary hypertension $90 \mathrm{~mm} \mathrm{Hg}$ or greater and left ventricular ejection fraction $25 \%$ or less, cardiomyopathy, or active endocarditis.

The OHI surgical team aims to complete as many successful surgeries as clinically possible within a 2 -week time-frame and to do so in a cost-efficient way. The multidisciplinary team includes 35 to 50 volunteers, licensed, medical, nursing, allied health, biomedical, and paramedical personnel and additional staff to manage data, transport, accommodation, and meals. All OHI staff undergo a police check (criminal record and working with children) from their home country with temporary "authority to practice" licensure obtained from the relevant Fijian Professional Registration boards. The OHI team collaborates with local medical and nursing staff on patient care provision across all domains of the surgical process, with training aimed at eventual in situ capability. Funds to cover the costs of surgery, estimated at $\$ 3500$ Australian dollars per patient, are completely met by donations from individual volunteers, medical companies, civic groups (eg, Rotary International and Lions Clubs International), and grants from AusAID (disbanded at the end of 2013) and the local Ministry of Health Fiji.

\section{Operative Process}

Over the 20-year time period reported, 19 surgeons conducted the surgery. A sternotomy approach and standard operative techniques are used for valve implantation and annuloplasty. Cardiopulmonary bypass is established on normothermia or mild hypothermia, antegrade or retrograde, and selective coronary artery retrograde cold blood cardioplegia is used for myocardial protection. For mitral VRs, the posterior leaflet apparatus is conserved. Whole blood cardioplegia is used on rewarming. Patients undergoing operation since $1999(\mathrm{n}=137)$ had intraoperative transesophageal echocardiography to confirm diagnoses and to assess valvular and prosthesis function. The majority $(\mathrm{n}=162,97 \%)$ of patients received a mechanical VR prosthesis. Between 1991 and 2005, all VR prostheses were from St Jude Medical Inc (St Paul, Minn). From 2006 to 2012, a combination of ATS (Medtronic Inc, Minneapolis, Minn) $(n=11)$, On-X (On-X Life Technologies, Inc) $(\mathrm{n}=8)$, and Edwards Lifesciences (Irvine, Calif) $(\mathrm{n}=2)$ prostheses were used, as well as the St Jude Medical prostheses. Patients living in remote regions and female patients of childbearing age are given the option of a biological prosthesis.

\section{Postoperative Follow-up}

The OHI surgical team remains in Suva to provide operative "on-call" for a minimum of 76 hours after the last operation has been performed. The OHI nursing team continues to work alongside local staff in the postoperative ward for a further 5 days.

Postoperative thromboprophylaxis is achieved using a combination of heparin, aspirin, and warfarin. Daily low-dose aspirin and twice-daily subcutaneous unfractionated heparin is administered. Warfarin is added on day 2 postoperatively with the adjunctive thromboprophylaxis continuing until an international normalized ratio (INR) of 2.0 is achieved. Patients are 
discharged from the hospital when the target INR is reached and remain in Suva for 6 weeks to attend the CWMH specialized outpatient department heart clinic for cardiac medication adjustments, INR level checks, warfarin-dose titration, and RHD prophylaxis. Target INRs are 2.5 to 3.5 for mitral or multiple VR recipients and 2.0 to 3.0 for isolated aortic valve recipients. ${ }^{14}$ Dysrhythmias such as atrial fibrillation are managed through electrolyte replacement and antiarrhythmic medications. If patients are still hospitalized when the $\mathrm{OHI}$ team leaves, care is transferred to the local medical and nursing team who work alongside the $\mathrm{OHI}$ team during their time in-country. There is local capability to manage prolonged ventilation or renal failure should this be required.

Standard postoperative instructions included advice on protecting the sternal split via restrictions on lifting, performing hard manual labor, gardening, and performing strenuous domestic duties for 3 months postoperatively. Additional advice included female patients being instructed to avoid unplanned pregnancy and male patients being instructed to avoid all contact sports. Lifelong attendance at a specialized outpatient department heart clinic is required monthly for anticoagulation monitoring, warfarin titration, and medication management.

\section{Data-Collection Process}

Data collection was undertaken during 6 field trips in-country over a 3-year period from 2009 to 2012. Patient details were obtained from the OHI Fiji surgical registry. A data-extraction tool was developed for the project, which included sociodemographic information, mortality, and morbidity. At the start of each data-collection cycle, patient records were reviewed at $\mathrm{CWMH}$, and visits were then made to referring hospitals, specialized outpatient department, and health clinics to extract additional information. Multiple patient records needed to be tracked, including accessing the centralized electronic record of patient visits and localized paper records at CWMH, referring hospitals, additional treating hospitals, and separate outpatient departments and village health clinic records. The last known villages of former patients were visited, and familial and friendship networks were used to locate patients lost to follow-up.

Complete follow-up data to death or last evaluation were obtained on $89.2 \%$ of the sample for a total of 624.9 patient years and a mean of 4.2 years (standard deviation, 4.24). Morbidity data were extracted for 152 patients $(91 \%)$, with 15 having no evidence of subsequent medical contact after hospital discharge. There were no statistically significant differences between the lost to follow-up group and the rest of the sample in gender, ethnicity, valve position, or operative age (data not shown).

\section{Outcomes}

Mortality and morbidity outcome data collected encompassed cerebral events, bleeding events, infective endocarditis, valve malfunction, sudden unexplained death, sternal infection, and heart failure. These data were based on guidelines for reporting morbidity and mortality after cardiac valve interventions. ${ }^{19}$ We report any death as "all-cause mortality" and any sudden, unexpected death or valve-related cause-of death, including infective endocarditis, as valve-related mortality. ${ }^{19}$ The causes of mortality and morbidity were obtained from medical records. MAVE was used to calculate event-free survival.

\section{Statistical Methods}

Comparisons of patient characteristics between groups were performed using the chi-square test or Fisher exact test where appropriate for categoric variables. One-way analysis of variance was used to test the continuous variable (age) against categoric variables. Kaplan-Meir survival curve actuarial analysis was used to delineate freedom from mortality, morbidity, and MAVE-free survival. Stratified survival curves were plotted to explore unadjusted differences for variables of interest, with differences in survival curves examined using the log-rank test. For multivariate analysis, binary
TABLE 1. Demographic and valve replacement characteristics of people undergoing valve replacement for rheumatic heart disease in Fiji

\begin{tabular}{|c|c|c|c|c|}
\hline & $\begin{array}{l}\text { Sample } \\
\mathrm{n}=167 \\
\end{array}$ & $\begin{array}{c}\text { Male } \\
\mathrm{n}=61 \\
\end{array}$ & $\begin{array}{l}\text { Female } \\
\mathrm{n}=\mathbf{1 0 6}\end{array}$ & $P$ \\
\hline & Mean (SD) & Mean (SD) & Mean (SD) & value* \\
\hline Age, y & $\begin{array}{c}26.1(11.7) \\
\text { n }(\%)\end{array}$ & $\begin{array}{c}23.3(9.8) \\
\text { n }(\%)\end{array}$ & $\begin{array}{c}27.7(12.5) \\
\text { n }(\%)\end{array}$ & .02 \\
\hline \multicolumn{5}{|l|}{ Ethnicity } \\
\hline $\begin{array}{l}\text { Fijian } \\
\text { Indo-Fijian or other }\end{array}$ & $\begin{array}{r}110(65.9) \\
57(34.1)\end{array}$ & $\begin{array}{l}43(70.5) \\
18(29.5)\end{array}$ & $\begin{array}{l}67(63.2) \\
39(36.8)\end{array}$ & .34 \\
\hline \multicolumn{5}{|l|}{ Valve replaced } \\
\hline Mitral & $87(52.1)$ & $28(46.0)$ & $59(55.6)$ & .22 \\
\hline Aortic & $32(1.2)$ & 17 (27.9) & 15 (14.2) & .03 \\
\hline Mitral + aortic & $27(16.2)$ & $12(19.7)$ & $15(14.2)$ & .35 \\
\hline $\begin{array}{l}\text { Mitral } \pm \text { aortic and } \\
\text { tricuspid ring } \\
\text { annuloplasty }\end{array}$ & $21(12.5)$ & $4(6.6)$ & $17(16.0)$ & .08 \\
\hline
\end{tabular}

logistic regression was used to identify predictors of mortality and morbidity, with each analysis adjusting for the following confounders: age, gender, ethnicity, and valve position. Statistical analyses were conducted using SPSS (SPSS Inc, Chicago, Ill). ${ }^{22}$

\section{RESULTS}

\section{Sample Characteristics}

A total of 167 people underwent VR surgery for RHD between 1991 and 2011, the most common being isolated mitral valve replacement (MVR) (52\%). The remainder underwent isolated aortic valve replacement (AVR) (19\%), MVR and AVR (16\%), and tricuspid ring annuloplasty in conjunction with MVR or AVR (13\%) (Table 1). The mean age of the sample was 26 years (standard deviation, 11.71), and most were female $(63 \%)$. Ethnicity was reflective of the general Fijian population, with approximately two thirds $(65.8 \%)$ ethnic-Fijian, $29.4 \%$ Indo-Fijian, and $4.8 \%$ other minority ethnic groups. ${ }^{16}$ Female patients were older than male patients by approximately 4 years $(P=.02)$, and female patients were less likely to have an isolated AVR compared with male patients $(14.2 \%$ vs $27.9 \%)(P=.03)$. Twenty-three post-VR pregnancies were recorded during the 20-year period, resulting in 13 live births.

\section{Mortality}

The overall mortality rate was $25.7 \%(\mathrm{n}=43)$, which peaked at 5 years postoperatively (Table 2). The mean time to death was 3.2 years $(95 \%$ confidence interval [CI], 1.91-4.43), and the mean survival time was 4.2 years (95\% CI, 3.54-4.79). Unadjusted actuarial survival time was 11.5 years $(95 \%$ CI, 9.45-13.60) (data not shown). Early mortality (0-90 days) was $8.4 \%$, and $2(1.2 \%)$ of these deaths occurred in hospital. Mortality at 30,60, and 
TABLE 2. Early, mid-term, and late mortality by gender of patients undergoing valve replacement surgery for rheumatic heart disease in Fiji

\begin{tabular}{|c|c|c|c|c|}
\hline Time & $\begin{array}{c}\begin{array}{c}\text { Sample } \\
(\mathrm{n}=167)\end{array} \\
\mathrm{n}(\%)\end{array}$ & $\begin{array}{c}\begin{array}{c}\text { Male patients } \\
(n=61)\end{array} \\
n(\%)\end{array}$ & $\begin{array}{c}\text { Female patients } \\
(\mathbf{n}=\mathbf{1 0 6})\end{array}$ & $\begin{array}{c}P \\
\text { value* },\end{array}$ \\
\hline \multicolumn{5}{|l|}{ Early } \\
\hline $30 \mathrm{~d}$ & $4(2.4)$ & $1(1.6)$ & $3(2.8)$ & .99 \\
\hline $60 \mathrm{~d}$ & $6(3.6)$ & $0(0.0)$ & $6(5.7)$ & .09 \\
\hline $90 \mathrm{~d}$ & $4(2.4)$ & $2(3.3)$ & $2(1.9)$ & .62 \\
\hline Total & $14(8.4)$ & $3(4.9)$ & $11(10.4)$ & .22 \\
\hline \multicolumn{5}{|l|}{ Mid-term } \\
\hline $1 \mathrm{y}$ & $6(3.6)$ & $1(1.6)$ & $5(4.7)$ & .42 \\
\hline $5 \mathrm{y}$ & $13(7.8)$ & $2(3.3)$ & $11(10.4)$ & .10 \\
\hline Total & 19 (11.4) & $3(4.9)$ & $16(15.1)$ & .05 \\
\hline \multicolumn{5}{|l|}{ Late } \\
\hline $10 \mathrm{y}$ & $7(4.2)$ & $2(3.3)$ & $5(4.7)$ & .99 \\
\hline $20 \mathrm{y}$ & $3(1.8)$ & $0(0.0)$ & $3(2.8)$ & .30 \\
\hline Total & $10(6.0)$ & $2(3.3)$ & $8(7.6)$ & .33 \\
\hline Total mortality & $43(25.7)$ & $8(13.1)$ & $35(33.0)$ & .005 \\
\hline
\end{tabular}

90 days was $2.4 \%, 3.6 \%$, and $2.4 \%$, respectively. Overall mid-term mortality (91 days to 5 years) was $11.4 \%$, and late mortality (5.01-20 years) was 6\%. Although one third $(\mathrm{n}=14,32.5 \%)$ of all 43 deaths occurred in the early postoperative period (0-90 days), a further 6 deaths occurred by the 1-year mark so that approximately half of all deaths occurred in the first postoperative year $(\mathrm{n}=20$, $46.5 \%$ ). From 1 to 5 years postoperatively, a further 13 deaths occurred so that two thirds of all mortality occurred within the first 5 years after surgery $(\mathrm{n}=33,76.7 \%)$. The most common cause of death was infective endocarditis followed by cardiogenic shock and cerebral events (Table 3). However, one quarter $(\mathrm{n}=12,27.9 \%)$ of the 43 patients who died had a "sudden unexplained death."

Female patients were more likely to die than male patients $(33 \%$ vs $13 \%, P=.005)$, particularly at mid-term $(15.1 \%$ vs $4.9 \%, P=.05)$. Comparison of actuarial survival by gender (Figure 1, A) showed a significant difference with estimated mean survival for male patients of 13.0 years (95\% CI, 10.70-15.23) versus 9.9 years $(95 \%$ CI, 7.80-12.47) for female patients $(P=.009)$.

\section{Morbidity}

Valve and RHD-related morbidity occurred in $25.7 \%$ of the sample (Table 4), with more than half of the 43 events occurring within the first postoperative year $(\mathrm{n}=24$, $55.8 \%)$. The mean time to event was 2.6 years $(95 \% \mathrm{CI}$, 1.39-3.83). On unadjusted actuarial analysis, freedom from event time was 11.2 years $(95 \% \mathrm{CI}, 9.52-12.96)$. Overall, early morbidity was $11.4 \%$, with 9 of these events
TABLE 3. Type of morbidity event and mortality cause of death

\begin{tabular}{|c|c|c|c|c|}
\hline Event type & $\begin{array}{c}\text { Sample } \\
(\mathrm{n}=167) \\
\mathrm{n}(\%)\end{array}$ & $\begin{array}{c}\begin{array}{c}\text { Male } \\
\text { patients } \\
(\mathbf{n}=61)\end{array} \\
\mathbf{n}(\%)\end{array}$ & $\begin{array}{c}\begin{array}{c}\text { Female } \\
\text { patients } \\
(\mathbf{n}=106)\end{array} \\
\mathbf{n}(\%)\end{array}$ & $\begin{array}{c}P \\
\text { value*, }\end{array}$ \\
\hline Cerebral event & $12(7.2)$ & $5(8.2)$ & $7(6.6)$ & .76 \\
\hline Bleeding event & $13(7.8)$ & $0(0.0)$ & $13(12.3)$ & .002 \\
\hline Infective endocarditis & $9(5.4)$ & $4(6.5)$ & $5(4.7)$ & .73 \\
\hline Heart failure & $8(4.8)$ & $1(1.6)$ & $7(6.6)$ & .26 \\
\hline Sternal infection & $1(0.6)$ & $0(0.0)$ & $1(0.9)$ & .99 \\
\hline Total morbidity & $43(25.7)$ & $10(16.4)$ & $33(31.1)$ & .04 \\
\hline \multicolumn{5}{|l|}{ Cause of death $\ddagger$} \\
\hline Cerebral event & $4(2.4)$ & $0(0)$ & $4(3.8)$ & .99 \\
\hline Hemorrhage & $2(1.2)$ & $0(0)$ & $2(1.9)$ & .99 \\
\hline Infective endocarditis & $7(5.0)$ & $3(4.9)$ & $4(3.8)$ & .11 \\
\hline Valve malfunction & $3(1.8)$ & $0(0)$ & $3(2.8)$ & .99 \\
\hline Heart failure & $4(2.4)$ & $0(0)$ & $4(3.8)$ & .99 \\
\hline Cardiogenic shock & $5(3.0)$ & $1(1.6)$ & $4(3.8)$ & .99 \\
\hline Sudden unexplained death & $12(7.2)$ & $3(4.9)$ & $9(8.5)$ & .67 \\
\hline $\begin{array}{l}\text { Unknown or other } \\
\text { noncardiac cause }\end{array}$ & $6(3.6)$ & $1(1.6)$ & $5(4.7)$ & .99 \\
\hline Total mortality & $43(25.7)$ & $8(13.1)$ & $35(33.0)$ & .005 \\
\hline
\end{tabular}

*Chi-square of Fisher exact test used for analysis, as applicable. $\dagger$ Comparison of each type of morbidity event and cause of death by gender. ‡Patients who died also may have had an admission for a morbidity event.

occurring in hospital (5.4\%). Morbidity at 30,60, and 90 days was $6.6 \%, 3.0 \%$, and $1.8 \%$, respectively. Mid-term morbidity was $10.8 \%$, and late morbidity was $3.6 \%$. Bleeding and cerebral events were the most common cause of morbidity followed by infective endocarditis and heart failure (Table 3). One patient required ongoing ventilation and renal dialysis and was transferred to Australia for treatment.

Survival analysis by gender showed a significant difference $(P=.04)$ in mean time of freedom from event with men at 12.5 years $(95 \% \mathrm{CI}, 10.30-14.76)$ and for women at 10.2 years $(95 \% \mathrm{CI}, 8.12-12.29)$ (Figure $1, B)$. Women had significantly more bleeding events than men $(12.3 \%$ vs $0 \%, P=.002)$ overall and during the early postoperative period $(P<.001)$, as well as more cerebral events at this time than men $(P=.01)$ (data not shown). Throughout mid- and late-term, women had significantly more readmissions for heart failure $(P<.001$ and $P=.02$ ), with men having more cerebral events $(P=.005)$ in the late postoperative period (data not shown).

\section{Freedom From Major Adverse Valve-Related Event}

Unadjusted survival analysis showed a mean time for freedom from MAVE as 10.1 years (95\% CI, 8.3-11.9) (data not shown). Female patients had a significantly shorter freedom from event time (mean, 9.1 years; $95 \%$ CI, 7.01-11.29 years) than male patients (mean, 11.4 years; 95\% CI, 8.96-13.76 years) $(P=.02)$. 

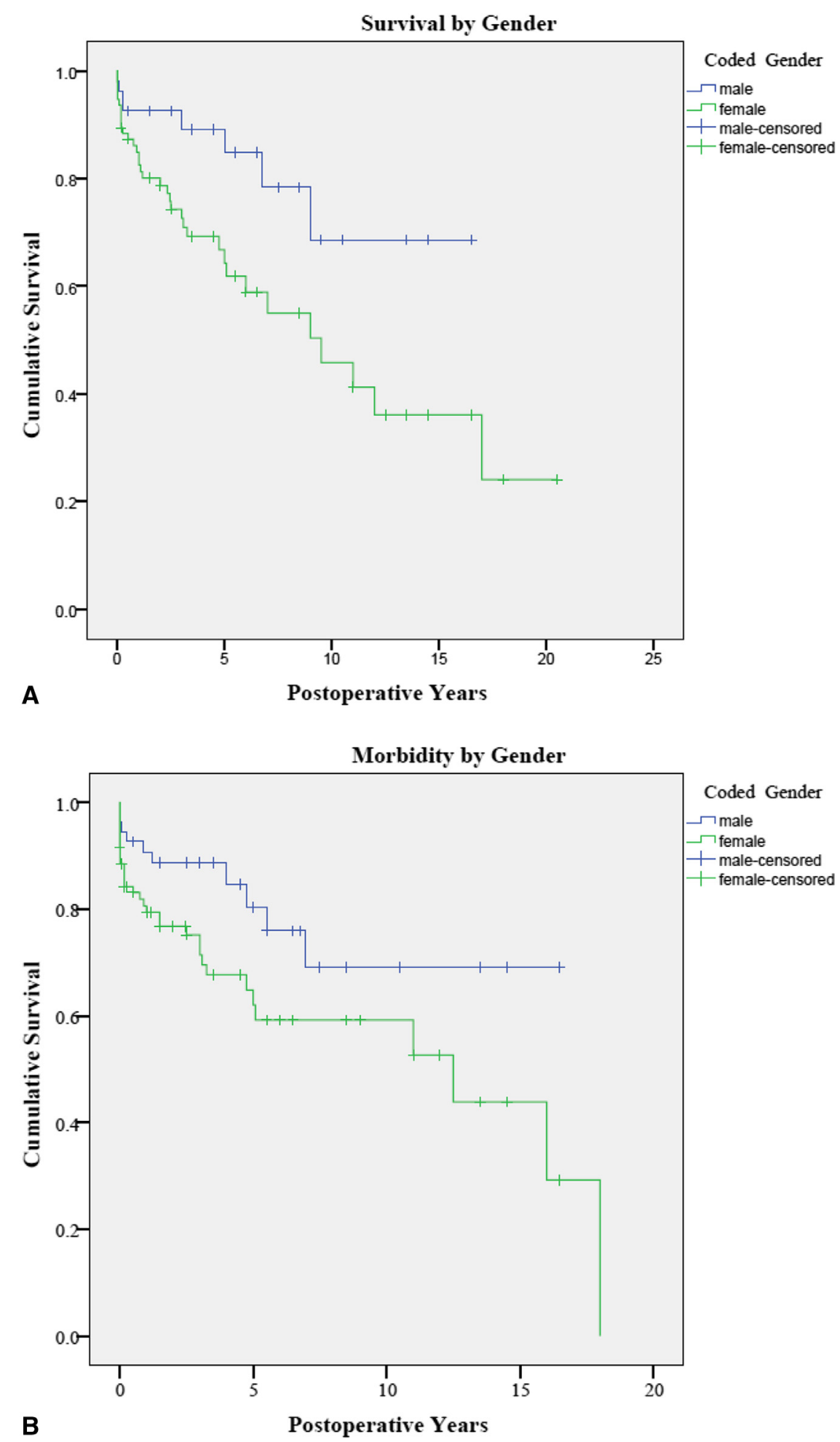

FIGURE 1. A, Cumulative survival by gender postoperatively. B, Cumulative morbidity-free survival by gender postoperatively.

\section{Predictors of Mortality and Morbidity}

By using logistic regression analysis and taking into account the type of valve surgery, age, and cultural background, the only independent predictor of mortality was gender. Women were 3 times more likely to die in the long-term after surgery than men (odds ratio [OR], 3.03; 95\% CI, 1.23-7.69). Undergoing an isolated MVR 
TABLE 4. Early, mid-term, and late morbidity of patients undergoing valve replacement surgery for rheumatic heart disease in Fiji

\begin{tabular}{|c|c|c|c|c|}
\hline & $\begin{array}{c}\text { Sample } \\
(\mathrm{n}=167) \\
\end{array}$ & $\begin{array}{l}\text { Male patients } \\
\quad(n=61) \\
\end{array}$ & $\begin{array}{c}\begin{array}{c}\text { Female } \\
\text { patients }(n=106)\end{array} \\
\end{array}$ & $P$ \\
\hline Time & $\mathbf{n}(\%)$ & $\mathbf{n}(\%)$ & n $(\%)$ & \\
\hline \multicolumn{5}{|l|}{ Early } \\
\hline $30 \mathrm{~d}$ & $11(6.6)$ & $2(3.3)$ & $9(8.5)$ & .16 \\
\hline $60 \mathrm{~d}$ & $5(3.0)$ & $0(0)$ & $5(4.7)$ & .16 \\
\hline $90 \mathrm{~d}$ & $3(1.8)$ & $2(3.3)$ & $1(0.9)$ & .56 \\
\hline Total & 19 (11.4) & $4(6.5)$ & $15(14.1)$ & .14 \\
\hline \multicolumn{5}{|l|}{ Mid-term } \\
\hline $1 \mathrm{y}$ & $5(3.0)$ & $1(1.6)$ & $4(3.8)$ & .65 \\
\hline $5 \mathrm{y}$ & $13(7.8)$ & $3(4.9)$ & $10(9.4)$ & .23 \\
\hline Total & $18(10.8)$ & $4(6.5)$ & $14(13.2)$ & .18 \\
\hline \multicolumn{5}{|l|}{ Late } \\
\hline $10 \mathrm{y}$ & $3(1.8)$ & $2(3.2)$ & $1(0.9)$ & .56 \\
\hline $20 \mathrm{y}$ & $3(1.8)$ & $0(0)$ & $3(2.8)$ & .30 \\
\hline Total & $6(3.6)$ & $2(3.2)$ & $4(3.8)$ & .99 \\
\hline Total morbidity & $43(25.7)$ & $10(16.4)$ & $33(31.1)$ & .04 \\
\hline
\end{tabular}

${ }^{*}$ Chi-square of Fisher exact test used for analysis, as applicable. $\dagger$ Comparison of each time period by gender.

or AVR was an independent predictor of reduced morbidity. The likelihood of a patient undergoing MVR having a morbidity event was $67 \%$ less (OR, $0.33 ; 95 \% \mathrm{CI}$, 0.12-0.93) and of a patient undergoing AVR was $76 \%$ less (OR, 0.34; 95\% CI, 0.06-0.96) than those who underwent VR surgery that included a tricuspid ring annuloplasty.

\section{DISCUSSION}

This is the first study to evaluate long-term follow-up after VR for RHD in the South Pacific, a region that has some of the highest rates of RHD in the world. . $^{2,-8,10}$ Within the context of high rates of premature mortality caused by RHD and limited access to valvular surgical intervention in Fiji, it is indisputable that fly-in/fly-out VR surgery provides the opportunity for a longer lifespan than would occur without intervention. However, aspects related to causes of morbidity and mortality and the increased vulnerability of female patients to both are concerning. Although the overall and sequential mortality and morbidity rates are comparable to VR data from the United States, the average age of people in this study at 26 years is considerably younger than US samples. ${ }^{23}$ Clearly, the potential benefits of VR surgery for resuming a productive life must be weighed against the morbidity and mortality risks, particularly because these are predominantly young people entering the most productive years of their lives.

It is well recognized that the highest risk time period for anticoagulation-related complications is within the first year after mechanical VR surgery, ${ }^{16}$ which is evident in this study. Approximately half of all mortality and morbidity occurred in the first postoperative year, and the causes were commonly thromboembolic and hemorrhagic. These outcomes are likely to be related to the availability of resources for surveillance and monitoring. One of the primary reasons that fly-in/fly-out teams are used in Fiji is the absence of cardiothoracic surgical resources. With a population of only 1 million and limited resources, countries like Fiji must always consider the benefits of fly-in/fly-out programs versus establishing in situ cardiac surgery services. Consequently, the patients in this Fijian sample are followed up at general heart clinics across the country rather than specialized cardiac-surgical clinics. There remains no formalized follow-up for nonattendance at clinic and no central point for ongoing referral, surveillance, and management of VR-related concerns. As new-generation anticoagulant therapies evolve, oral alternatives to warfarin such as dabigatran (Pradaxa, Boehringer Ingelheim, Ingelheim am Rhein, Germany), a direct thrombin inhibitor, which do not require ongoing regular INR testing and titration, may be considered. ${ }^{24}$ Currently, dabigatran has not been approved for use in VR anticoagulation regimens and is more expensive than warfarin.

Comparable VR populations who are served by fly-in fly-out teams are largely unpublished; however, in situ programs conducted in Pakistan and West Africa ${ }^{25-27}$ have lower rates of mortality and morbidity but also have strictly supervised follow-up regimens that encompass anticoagulation monitoring and titration, RHD, and endocarditis prophylaxis prevention, and are managed by experienced cardiac clinicians. In these studies, patients received formal discharge education regarding anticoagulation management and RHD prophylaxis, echocardiograms at 3 months, and 1 year postdischarge thence annually, and close surveillance of subsequent INR levels. In the West African study, ${ }^{27}$ all VR surgery was performed in Ghana with many patients living more than $100 \mathrm{~km}$ from the facility. Regular follow-up was achieved by having INRs attended at the patient's local facilities with warfarin dosage titration managed by telephone consultation and reattendance at the Ghanaian clinic every 12 weeks, instead of the usual 4 weeks. The comprehensive educational and follow-up programs discussed in these studies provide feasible strategies for long-term surveillance that would serve as good models for other developing countries, such as Fiji, because of similarities in patient type, access, and resource limitations. One of the most important aspects of such systematic approaches is that RHD is more likely to be detected and treated early. Valve damage may then be less extensive and valve repair more possible than in the current study, therefore limiting the need for anticoagulation and associated risks.

Female patients were identified to be at a higher risk of mortality and morbidity, particularly related to bleeding events. Potential explanation lies in a combination of 
factors: the difficulties with follow-up explained earlier, gender-specific issues arising out of mechanical prosthesis implantation and anticoagulation in women (menstruation, pregnancy, childbirth), and traditional gender roles for women in Fiji. ${ }^{28}$ Although there have been many positive changes in the country, the disparity between genders on measurable factors such as paid employment and education levels is high. ${ }^{29}$ The traditional female role is secondary and includes responsibility for domestic-linked domains, including child-rearing and home duties, regardless of concomitant paid employment. ${ }^{28}$ It is probable that familial and social obligations intertwined with transport costs and the substantial amount of time required away from home or employment to attend the monthly clinic may be obstacles to accessing continued care and influence the poorer outcomes for female patients in this study. Poverty also may be an important factor with a study of barriers to accessing health care by women, undertaken in the neighboring Pacific country of Vanuatu, identifying the economic status of the household to which women belong as a key factor predictive of healthcare use. ${ }^{30}$ Women living in poorer households were 5 times less likely to access health care than those who were relatively affluent. ${ }^{30}$

Further research evaluating regularity of clinic attendance and access, household income, and other factors, including more detailed clinical data, is required to identify reasons for increased female vulnerability to negative outcomes. In particular, outcomes for women who are pregnant need to be determined as a basis for further debate around the choice of valve prosthesis or repair given the risks women face during pregnancy and childbirth when taking anticoagulant medication.

The causes of morbidity in this study were closely aligned with the causes of mortality, and as previously discussed, patients would benefit from additional surveillance along with education for both patients and health staff. Ideally, this would include predischarge education on RHD prophylaxis, dental interventions and endocarditic prophylaxis, the importance of maintaining therapeutic anticoagulation and regular follow-up checks at clinic, and advice on conception and pregnancy management. Collaboration between the surgical team and the local medical team to more closely support long-term follow-up is essential and could be incorporated into local systems for RHD surveillance and treatment. Inexpensive options, such as mobile technology (group text messaging) currently used by the Fiji Ministry of Health to obtain volunteers for blood-bank donations, could be used to support follow-up.

\section{Study Limitations}

This study identified having an isolated VR as an independent predictor of a decreased risk of morbidity. The need for multiple VR is indicative of the severity of the RHD, and physiologic cardiac function is generally more compromised. ${ }^{13}$ However, without precise, documented echocardiographic data with which to evaluate disease severity, this explanation is speculative.

Data collection was dependent on the information available in the medical records. Important data on echocardiographic findings, preoperative and postoperative functional status, long-term INR, and medication records were unavailable. Although patients may have had an echocardiogram, the results were not documented consistently. In addition, having a large number of deaths as "sudden and unexpected" without having an identified cause has reduced the ability to fully evaluate the causes of death and consequently accurately compare the "cause of death" outcomes from this study with those of other populations. $^{17,25-27,31-33}$

\section{CONCLUSIONS}

This study shows that the majority of people undergoing VR surgery for RHD in Fiji by the OHI have good outcomes. Improvement in discharge education, ongoing support, long-term surveillance, particularly for female patients, and appropriate anticoagulation management is required. Resources need to be prioritized toward closer long-term medical surveillance because there is evidence from other studies that better outcomes after VR surgery are achievable. Future research should include prospective data collection on important cardiac function parameters and potentially preventable mortality and morbidity events. Such research should include specific data on echocardiography measures, preoperative and postoperative functional status, and INR levels over time to enable exploration of the relative contribution of these to postoperative outcomes.

\section{References}

1. World Health Organization. WHO Expert Consultation on Rheumatic Fever and Rheumatic Heart Disease. WHO Technical Report Series. No. 923. Geneva, Switzerland: WHO; 2004

2. Steer AC, Carapetis JR, Nolan TM, Shann F. Systematic review of rheumatic heart disease prevalence in children in developing countries: the role of environmental factors. J Paediatr Child Health. 2002;38:229-34.

3. Carapetis JR, Steer AC, Mulholland EK, Weber M. The global burden of group A streptococcal diseases. Lancet Infect Dis. 2005;5:685-94.

4. Carapetis JR. Rheumatic heart disease in developing countries. $N$ Engl J Med. 2007;357:439-41.

5. Viali S. Rheumatic fever and rheumatic heart disease in Samoa. Pac Health Dialog. 2006;13:31-8.

6. Steer AC, Kado J, Jenney AWJ, Batzloff M, Waqatakirewa L, Mulholland EK, et al. Acute rheumatic fever and rheumatic heart disease in Fiji: prospective surveillance, 2005-2007. Med J Aust. 2009;190:133-5.

7. Reeves BM, Kado J, Brook M, Reeves BM, Kado J, Brook M. High prevalence of rheumatic heart disease in Fiji detected by echocardiography screening. J Paediatr Child Health. 2011;47:473-8.

8. Singh PIPK, Carapetis JR, Buadromo EM, Samberkar PN, Steer AC. The high burden of rheumatic heart disease found on autopsy in Fiji. Cardiol Young. 2008; 18:62-9.

9. Carapetis JR, Hardy M, Fakakovikaetau T, Taib R, Wilkinson L, Penny DJ, et al. Evaluation of a screening protocol using auscultation and portable echocardiography to detect asymptomatic rheumatic heart disease in Tongan schoolchildren. Nat Clin Pract Cardiovasc Med. 2008;5:411-7. 
10. Viali S, Saena P, Futi V. Rheumatic Fever Programme in Samoa. N Z Med J. 2011; 124:26-35.

11. Steer A, Colquhoun S, Noonan S, Kado J, Viale S, Carapetis J. Control of rheumatic heart disease in the Pacific region. Pacific Health Dialog. 2006;13:49-55.

12. Cuboni HD, Finau SA, Cuboni G. Rheumatic fever and rheumatic heart diseases in Fiji: a review from the surveillance system (1996-2000). Pacific Health Dialog. 2006;13:39-47.

13. Bonow RO, Mann DL, Zipes DP, Libby P, eds. Braunwald's Heart Disease: A Textbook of Cardiovascular Medicine. 9th ed. Philadelphia, PA: Saunders, an imprint of Elsevier Inc. International Edition; 2012.

14. Bonow RO, Carabello BA, Chatterjee K, de Leon AC Jr, Faxon DP, Freed MD, et al. 2008 Focused update incorporated into the ACC/AHA 2006 guidelines for the management of patients with valvular heart disease: a report of the American College of Cardiology/American Heart Association Task Force on Practice Guidelines (Writing Committee to Revise the 1998 Guidelines for the Management of Patients With Valvular Heart Disease): endorsed by the Society of Cardiovascular Anesthesiologists, Society for Cardiovascular Angiography and Interventions, and Society of Thoracic Surgeons. Circulation. 2008;118: e523-661.

15. National Heart Foundation of Australia (RF/RHD Guideline Development Working Group) and the Cardiac Society of Australia and New Zealand. Diagnosis and management of acute rheumatic fever and rheumatic heart disease in Australia - an evidence-based review. 2006. National Heart Foundation of Australia 2006.

16. Kulik A, Rubens FD, Wells PS, Kearon C, Mesana TG, van Berkom J, et al. Early postoperative anticoagulation after mechanical valve replacement: a systematic review. Ann Thorac Surg. 2006;81:770-81.

17. Davis PJ, Wainer Z, O'Keefe M, Nand P. Cardiac surgery in the Pacific Islands. ANZ J Surg. 2011;81:871-5.

18. Tefuarani N, Vince J, Hawker R, Nunn G, Lee R, Crawford M, et al. Operation Open Heart in PNG, 1993-2006. Heart Lung Circ. 2007;16:373-7.

19. Akins CW, Miller DC, Turina MI, Kouchoukos NT, Blackstone EH, Grunkemeier GL, et al. Guidelines for reporting mortality and morbidity after cardiac valve interventions. Ann Thorac Surg. 2008;85:1490-5.

20. Roberts G, Irava W, Tuiketei T, Nadakuitavuki R, Otealagi S, Singh S, et al. The Fiji Health System Review. Geneva: The Asia Pacific Observatory on Health Systems and Policies; 2011.

21. Were M. Healthcare Outreach: About Operation Open Heart. 2012. Available at: http://www.ooh.org.au/about. Accessed October 8, 2012.
22. PASW Statistics. Chicago IL: SPSS Inc; 2009.

23. Allareddy V, Ward MM, Ely JW, Levett J. Impact of complications on outcomes following aortic and mitral valve replacements in the United States. J Cardiovasc Surg (Torino). 2007;48:349-57.

24. Connolly SJ, Ezekowitz MD, Yusuf S, Eikelboom J, Oldgren J, Parekh A, et al. Dabigatran versus warfarin in patients with atrial fibrillation. $N$ Engl J Med. 2009;361:1139-51

25. Akhtar RP, Abid AR, Naqshband MS, Mohydin BS, Khan JS, Akhtar RP, et al Outcome of double vs. single valve replacement for rheumatic heart disease. J Coll Physicians Surg Pak. 2011;21:9-14.

26. Akhtar RP, Abid AR, Zafar H, Sheikh SS, Cheema MA, Khan JS. Prosthetic valve replacement in adolescents with rheumatic heart disease. Asian Cardiovasc Thorac Ann. 2007; 15:476-81.

27. Edwin F, Aniteye E, Tettey MM, Tamatey M, Frimpong-Boateng K, Edwin F, et al. Outcome of left heart mechanical valve replacement in West African children-a 15-year retrospective study. J Cardiothorac Surg. 2011;6:57.

28. Griffen V, ed. Women, Development and Empowerment: A Pacific Feminist Perspective. Report of a Pacific Women's Workshop, Naboutini, Fiji, 23-26 March 1987. Fiji: Asian and Pacific Development Centre, Kuala Lumpur, Malaysia; 1989.

29. Organisation for Economic Co-operation and Development. Social Institutions and Gender Index; Fiji. Available at: http://genderindex.org/country/ fiji. Accessed November 12, 2013.

30. Rahman M, Haque SE, Mostofa MG, Tarivonda L, Shuaib M. Wealth inequality and utilization of reproductive health services in the Republic of Vanuatu: insights from the multiple indicator cluster survey, 2007. Int J Equity Health 2011;10:58

31. Yau TM, El-Ghoneimi YAF, Armstrong S, Ivanov J, David TE. Mitral valve repair and replacement for rheumatic disease. J Thorac Cardiovasc Surg. 2000;119:53-61.

32. Kim JB, Kim HJ, Moon DH, Jung SH, Choo SJ, Chung $\mathrm{CH}$, et al Long-term outcomes after surgery for rheumatic mitral valve disease: valve repair versus mechanical valve replacement. Eur J Cardiothorac Surg. 2010; 37:1039-46.

33. Travancas PR, Dorigo AH, Simoes LC, Fonseca SC, Bloch KV, Herdy GV. Comparison of mechanical and biological prostheses when used to replace heart valves in children and adolescents with rheumatic fever. Cardiol Young. 2009;19: 192-7. 